\title{
CIC-5 chloride channel and kidney stones: what is the link?
}

M.M. Morales and A.G. Lopes
Laboratório de Fisiologia Renal, Instituto de Biofísica Carlos Chagas Filho, Universidade Federal do Rio de Janeiro, Rio de Janeiro, RJ, Brasil

\section{Correspondence}

A.G. Lopes

Laboratório de Fisiologia Renal

Instituto de Biofísica

Carlos Chagas Filho, UFRJ

21949-900 Rio de Janeiro, RJ

Brasil

Research supported by PADCT, CNPq, FINEP, Fundação U niversitária José Bonifácio, FAPERJ and FAPESP.

Received May 16, 2000

Accepted January 9, 2001

\section{Abstract}

Nephrolithiasis is one of the most common diseases in the Western world. The disease manifests itself with intensive pain, sporadic infections, and, sometimes, renal failure. The symptoms are due to the appearance of urinary stones (calculi) which are formed mainly by calcium salts. These calcium salts precipitate in the renal papillae and/ or within the collecting ducts. Inherited forms of nephrolithiasis related to chromosome $\mathrm{X}$ (X-linked hypercalciuric nephrolithiasis or XLN) have been recently described. Hypercalciuria, nephrocalcinosis, and male predominance are the major characteristics of these diseases. The gene responsible for the XLN forms of kidney stones was cloned and characterized as a chloride channel called $\mathrm{ClC}-5$. The ClC-5 chloride channel belongs to a superfamily of voltage-gated chloride channels, whose physiological roles are not completely understood. The objective of the present review is to identify recent advances in the molecular pathology of nephrolithiasis, with emphasis on XLN. We also try to establish a link between a chloride channel like ClC-5, hypercalciuria, failure in urine acidification and protein endocytosis, which could explain the symptoms exhibited by XLN patients.

\section{Is nephrolithiasis a matter of imbalances in mineral metabolism?}

Nephrolithiasis (or kidney stones) is one of the most common diseases in countries like the USA, United Kingdom, Japan, and Brazil (1-4). Most of the patients present recurrent kidney stones and metabolic disorders (5-7). Male patients predominate, but about $30 \%$ of patients are female (1-3).

Most calculi found in patients with kidney stones are formed by calcium salts, mainly calcium phosphate and calcium oxalate (810). Calculi formed by cystine (a dimer of cysteine), urate, and struvite $\left(\mathrm{Mg}\left(\mathrm{NH}_{4}\right) \mathrm{PO}_{4}\right)$
Key words

- Nephrolithiasis

- Dent's disease

- Calcium reabsorption

- Chloride channels are found less frequently (1). The fact that calculi are mainly formed by calcium salts has led many investigators to speculate about a possible problem in calcium homeostasis (1). Although several investigators have explored this hypothesis, there are no conclusive data about this mechanism of stone formation.

Important advances have been recently made with the identification of inherited forms of nephrolithiasis. Several genes have been identified by genetic mapping of families with a history of kidney stones. Among these genes are the cystine transporter, which is defective in autosomal recessive cysti- 
nuria (11), the calcium sensing receptor (12), and the voltage-gated chloride channel $\mathrm{ClC}$ 5 (for a review, see Ref. 13), on which we focus this review.

Data involving ClC-5 in the pathogenesis of nephrolithiasis have been recently reviewed by Scheinman (14). In the present review we point out the postulated roles that ClC-5 could have in the pathogenesis of nephrolithiasis. Also, we try to establish a link between this chloride channel and stone formation.

\section{The CIC-5 chloride channel and $\mathrm{X}$-linked recessive nephrolithiasis: are they just variants or different diseases?}

Dent's disease was first reported by Dent and Friedman in 1964 (15). At that time, they identified this disease as a form of Fanconi's syndrome due to impairment of renal acidification similar to that observed in such patients (15). Besides the renal acidification

Table 1 - A summary of the main symptoms caused by the variants of $X$-linked hypercalciuric nephrolithiasis (XLN) and the symptoms detected in a study of idiopathic nephrolithiasis patients in the USA and Brazil (Refs. 5,60).

Male predominance, hypercalciuria, and low molecular weight (LMW) proteinuria are present in all XLN patients. However, rickets, calcium stones, and renal failure vary among syndromes. Several mutations in $\mathrm{CICN} 5$ are found in these syndromes. Nevertheless, mutation in $\mathrm{ClC}-5$ was detected in just one person among 32 patients with idiopathic hypercalciuric nephrolithiasis. No study addressing CICN5 mutations or a characterization of a syndrome closely related to Dent's disease is available for the Brazilian patients. ND, Not determined. (Modified from Ref. 17, with permission). *Found in just one patient (Ref. 60).

\begin{tabular}{|c|c|c|c|c|c|c|}
\hline $\begin{array}{l}\text { X-Linked recessive } \\
\text { syndrome }\end{array}$ & XLN & $\begin{array}{l}\text { Dent's } \\
\text { disease }\end{array}$ & $\begin{array}{l}\text { X-Linked } \\
\text { recessive }\end{array}$ & $\begin{array}{l}\text { LMW proteinuria/ } \\
\text { nephrocalcinosis }\end{array}$ & $\begin{array}{r}\text { Idio } \\
\text { nephr }\end{array}$ & $\begin{array}{l}\text { thic } \\
\text { thiasis }\end{array}$ \\
\hline Source of reports & $\begin{array}{l}\text { USA, } \\
\text { Canada }\end{array}$ & UK & $\begin{array}{l}\text { Italy, } \\
\text { France }\end{array}$ & J apan & USA & Brazil \\
\hline LMW proteinuria & + & + & + & + & - & ND \\
\hline Hypercalciuria & + & + & + & + & + & + \\
\hline Nephrocalcinosis & + & + & + & - & + & + \\
\hline Calcium stones & - & + & + & - & + & + \\
\hline Renal failure & - & + & + & + & - & ND \\
\hline Male predominance & + & + & + & - & + & - \\
\hline Rickets & - & + & + & + & - & - \\
\hline CICN5 mutations & + & + & + & + & $t^{*}$ & $?$ \\
\hline
\end{tabular}

impairment, Dent's disease patients also exhibited rickets, hypercalciuria, nephrocalcinosis, low molecular weight (LMW) proteinuria, and nephrolithiasis (14-17). Progressive renal failure may occur in the late stages of Dent's disease $(14,16,17)$.

Several reports have identified other syndromes with phenotypes similar to that of Dent's disease. These diseases have been called X-linked recessive nephrolithiasis in the USA, X-linked recessive hypophosphatemic rickets in Italy, and LMW proteinuria with hypercalciuria and nephrocalcinosis in Japan (14). Although these syndromes have hypercalciuria, LMW proteinuria, and nephrocalcinosis in common, rickets and renal failure are not always present in all of them (16). Table 1 summarizes the common symptoms and their occurrence among the variants. Also, Table 1 shows mutations in the ClC-5 characterizing idiopathic nephrolithiasis in the USA and the characteristics of nephrolithiasis in Brazil.

Pedigree analysis of families with Dent's disease revealed that this syndrome may be linked to the $\mathrm{X}$ chromosome. After 30 years, Thakker and colleagues (18-21) finally identified the locus responsible for the gene defect in the 11.22 region of the $\mathrm{X}$ chromosome. Further isolation of the gene encoded by this region showed that its product was a chloride channel, called ClC-5 (19).

The ClC-5 chloride channel belongs to a family of voltage-gated chloride channels and its predicted structure is shown in Figure 1 . This growing family already has 9 cloned members $(22,23)$. At least two other members of this family, $\mathrm{ClC}-1$ and $\mathrm{ClC}-\mathrm{K}_{\mathrm{B}}$, are involved in diseases.

ClC-1 is defective in Thomsen's myotonia. There is evidence that the wild-type ClC-1 channel maintains the membrane potential in muscle cells after excitation $(19,21)$. Thus, loss of function of ClC-1 leads to permanent muscle excitation and excessive contractile activity. A kidney-specific chloride channel, $\mathrm{ClC}-\mathrm{K}_{\mathrm{B}}$, was shown to be mu- 
tated in Bartter's syndrome which is characterized by electrolyte loss (24). The localization of $\mathrm{ClC}-\mathrm{K}_{\mathrm{B}}$ in the basolateral membrane of the thin ascending limb of Henle's loop as well as its regulation by dehydration suggest a role in the mechanism of urinary concentration (25).

Lloyd and coworkers (26) showed that the mutant $\mathrm{ClC}-5$ found in patients with Dent's disease has lower conductance than the wild-type chloride channel. They also characterized several mutations of the $\mathrm{ClC}-5$ gene in patients with $\mathrm{X}$-linked recessive nephrolithiasis, X-linked hypophosphatemic rickets, and LMW proteinuria with hypercalciuria and nephrocalcinosis, showing that these diseases are just variations of a single pathology $(26,27)$. All mutants exhibited loss of function when compared to wild-type ClC-5, suggesting that $\mathrm{ClC}-5$ is needed for normal renal function. These syndromes were then grouped under the same name of $\mathrm{X}$ linked hypercalciuric nephrolithiasis (XLN) by Scheinman (14).

The information that the ClC-5 channel could be the molecular entity responsible for stone formation led several researchers to investigate the molecular basis of the disease. Although mutations were found within the $\mathrm{ClC}-5$ gene, no apparent relation be- tween stone formation and a chloride channel was detected. The literature on $\mathrm{ClC}-5$ and XLN will be discussed in the next sections.

\section{CIC-5 chloride channel and protein endocytosis}

The majority of patients with XLN also have LMW proteinuria (14,26-28). It is well known that LMW proteins are reabsorbed in the $\mathrm{S}_{2}$ and $\mathrm{S}_{3}$ segments of the proximal tubules, where several proteins filtered by the glomerulus are endocytosed and degraded within the lysosomes, providing the uptake of the amino acids (29).

ClC-5 is found in the $S_{2}$ and $S_{3}$ segments of proximal tubules, mainly in immediately early endosomes (30-35). Also, Devuyst et al. (35) demonstrated that proximal tubule cells transfected with $\mathrm{ClC}-5$ are able to endocytose albumin and that the channel colocalizes with the albumin present in the endosomes. These data suggest a possible role of ClC-5 in non-receptor-mediated endocytosis, explaining the LMW proteinuria found in such patients.

Some hypotheses about the role of ClC-5 in the endosomes have been raised. Within the lysosomes several proteases work in an

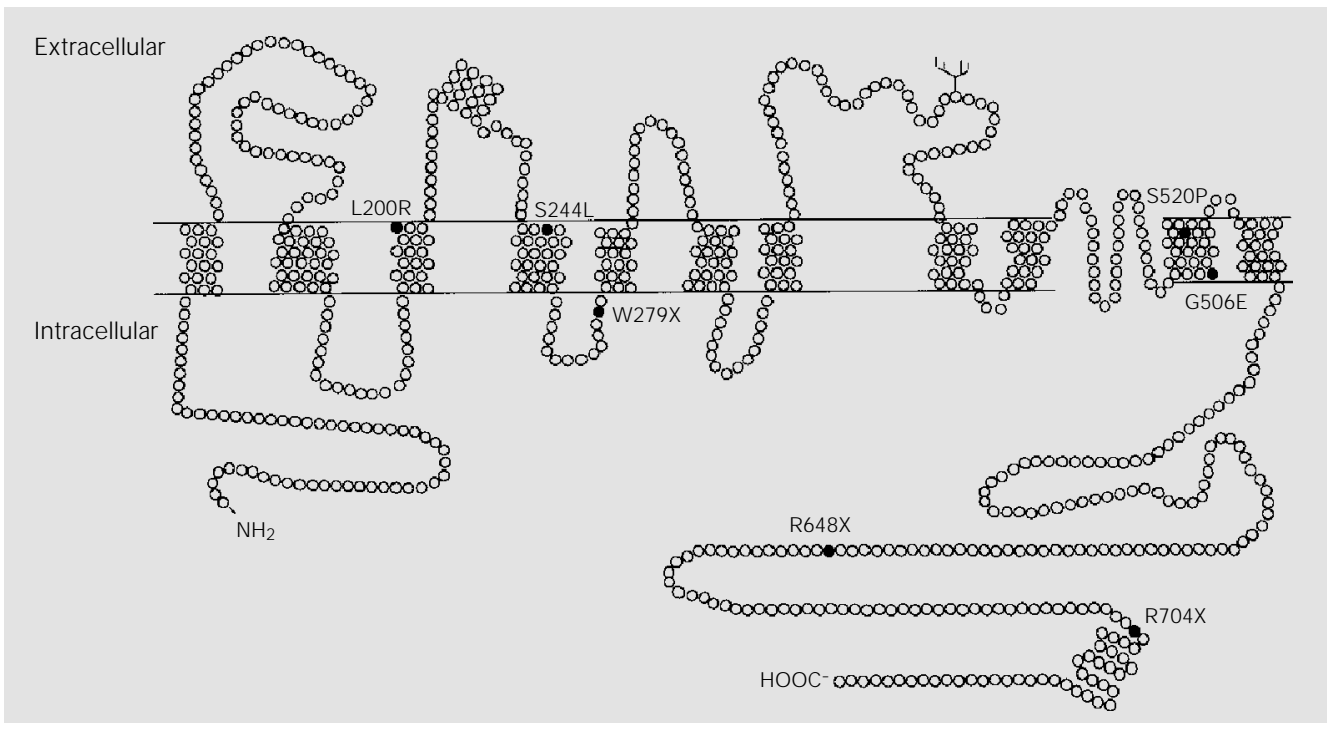

Figure 1 - Predicted two-dimensional structure of the $\mathrm{ClC}-5$ chloride channel. Deduction of amino acids from CIC-5 CDNA predicts 13 transmembrane domains. Although there is a potential site for CAM P-dependent protein kinase, analogs of CAMP do not change the current of the CIC-5 channel (Refs. 40,41) Some common mutations in XLN patients are represented by black circles and the mutated amino acids are indicated (obtained from Ref. 26). 
acidic environment provided by the vacuolar $\mathrm{H}^{+}$-ATPase (31-33). The transport of a positively charged ion such as $\mathrm{H}^{+}$should be followed by an anion, such as $\mathrm{Cl}^{-}$, to maintain electroneutrality within the organelle. As long as it is present in the endosomes, ClC-5 may allow the transport of chloride through the endosomal membrane $(31,32,34$, 35). Therefore, loss of ClC-5 function may lead to impairment of $\mathrm{H}^{+}$-ATPase activity which would decrease the $\mathrm{pH}$ inside the endosome. Moreover, the failure in organelle acidification may lead to a decrease in protein endocytosis, and therefore, to the LMW proteins excreted in urine by XLN patients.

ClC-5 is found in endosomes but not in lysosomes (31-33). Acidic secretion also occurs in lysosomes and therefore they should also have a system for $\mathrm{Cl}^{-}$transport. Hence, chloride channels other than $\mathrm{ClC}-5$ may be present in lysosomes $(34,35)$. Thus, it is reasonable to assume that $\mathrm{ClC}-5$ contributes to $\mathrm{Cl}^{-}$transport in the late endosome, but it is not clear how the channel works when the endosome becomes a lysosome.

Deficiency in endocytosis is supposed to be lethal due to its role in cellular nutrition. In rats, $\mathrm{ClC}-5$ is expressed in other tissues besides the kidney, such as brain, lungs, liver, endothelial cells, and colon (31-33,36). In addition, the human $\mathrm{ClC}-5$ channel is also expressed in endothelial cells, suggesting that the distribution of ClC-5 may not be restricted to the kidney (37). It is well known that protein endocytosis takes place in liver, endothelial cells, and colon. However, in XLN patients no disorders in endocytosis are observed in any other organs in addition to the kidney. Moreover, neither symptoms due to chloride channel defects nor dysfunction in endocytosis were detected in the endothelium. Thus, it is not understood how this important function could be impaired only in the kidney.

Several investigators have postulated that in the renal tubule the calculi are cleared by endocytosis $(8,9,38,39)$. This mechanism would lead to fewer stones, lesser calculus formation, and thus, amelioration of the symptoms. Thus, besides having a role in protein endocytosis, the $\mathrm{ClC}-5$ channel may also be responsible for the clearance of the calculi formed within the kidney tubules since both protein and calculi are endocytosed by similar mechanisms $(29,38,39)$. Taken together, the data addressing the role of ClC-5 in protein endocytosis indicate that ClC-5 may also be important for calculus clearance. However, further studies are necessary to clarify its role in calculus endocytosis.

\section{CIC-5 chloride channel and urine acidification}

Alkaline urine is a common sign found in Fanconi's syndrome patients (15). Although Dent's disease is currently characterized as an independent pathology, a urine acidification disorder was also found in some patients (13-17). It is well known that alkaline urine enhances the precipitation of calcium salts resulting in kidney stones $(1,8,9)$. However, urine alkalization is not as widespread as hypercalciuria and LMW proteinuria in XLN patients (14-17).

Since the first report of ClC-5 mRNA localization several speculations have been made about its role in urinary acidification $(32,40-43)$. ClC-5 mRNA and protein are expressed in the intercalated cells of collecting ducts $(32,33,38,44)$. These cells are responsible for proton $\left(\mathrm{H}^{+}\right)$secretion and, therefore, urine acidification. Working independently, Gunther et al. (33) and Sakamoto and coworkers (44) showed that the ClC-5 protein colocalizes with $\mathrm{H}^{+}$-ATPase on the plasma membranes of type $\mathrm{A}$ intercalated cells from collecting ducts.

It is reasonable to assume that there should be $\mathrm{Cl}^{-}$conductance to maintain electroneutrality of $\mathrm{H}^{+}$secretion as well as within the endosome. To propose that $\mathrm{Cl}^{-}$secretion may occur through the $\mathrm{ClC}-5$ channel it is 
necessary to show that ClC-5 is also expressed on the luminal plasma membrane, as demonstrated by Gunther and coworkers (33). In agreement with Gunther and coworkers, Friedrich et al. (45) have shown that ClC-5 is indeed expressed as plasma membrane conductance in Xenopus oocytes. In addition, Mo et al. (46) demonstrated that $\mathrm{ClC}-5$ is inhibited by a decrease in extracellular $\mathrm{pH}$. Therefore, the ClC-5 channel is sensitive to mild changes in $\mathrm{pH}$, with down-regulation of the channel when the $\mathrm{pH}$ decreases. This seems to be an excellent regulatory mechanism in both the intra-endosomal space and the tubular lumen. However, some contradictory data have ruled out this hypothesis.

First of all, Luyckx et al. (34) did not show the expression of ClC-5 in intercalated cells. They showed that this channel is mainly present in subcellular compartments but not on the plasma membrane. Also, animals with lower expression of $\mathrm{ClC}-5$ do not have any problem in urine acidification when compared with normal littermates (47). In fact, despite the pattern of expression and its regulation by $\mathrm{pH}$, there are no other data consistently relating $\mathrm{ClC}-5$ dysfunction to urine alkalization. Once again, further experiments are necessary to confirm the role of $\mathrm{ClC}-5$ in urine acidification.

\section{The role of CIC-5 in mineral metabolism}

Hypercalcuria is another major symptom of XLN (14-17). The hypothesis that higher levels of urinary calcium lead to precipitation of calcium salts and then to stone formation is well accepted today $(1,2,8,9)$. Although $\mathrm{ClC}-5$ seems to be expressed mainly in the human kidney (the major site of the disease), it is also expressed in rat colon, brain, and lungs $(33,34,36-38,48,49)$ and in Xenopus oocytes (50).

The distribution of ClC-5 mRNA along the rat nephron reveals that this chloride channel is more abundant in the $S_{3}$ segments of proximal tubules, in the cortical and medullary thick ascending limb of Henle's loop, and in cortical collecting ducts (CCD) $(33,34$, 36,37). An independent group using in situ hybridization further confirmed the expression of the ClC- 5 channel on these segments (32). The localization of ClC-5 matches the major sites of calcium reabsorption in the kidney (51). Thus, localization of ClC-5 in the nephron segments responsible for calcium reabsorption and for the hypercalciuric phenotype exhibited by XLN patients suggested a role of ClC-5 in calcium transport. Therefore, a failure in ClC-5 function would lead to hypercalciuria. However, the relationship between $\mathrm{ClC}-5$ and calcium metabolism has only recently been investigated.

Silva et al. (52) have shown that parathormone $(\mathrm{PTH})$ regulates $\mathrm{ClC}-5$ expression in vivo in an animal model of disturbed calcium homeostasis. The authors showed that vitamin D-deficient and thyroparathyroidectomized animals have a lower (about $50 \%$ ) expression of ClC-5 mRNA in the kidney cortex. The expression of ClC-5 returned to normal values when the animals were treated with PTH. These data are reproducible when the $\mathrm{ClC}-5$ protein is analyzed by Western blots. It is well known that PTH enhances calcium reabsorption by the kidney and that the major site of this action is the kidney cortex (51). Animals with low or almost no expression of $\mathrm{ClC}-5$ have high urinary calcium excretion (52). These data suggest that $\mathrm{ClC}-5$ is necessary for calcium reabsorption in the kidney.

Although it may be not clear how a chloride channel could enhance calcium reabsorption, Gesek and Friedman (49) showed a functional chloride channel in cultured CCD cells which reabsorb calcium under PTH and calcitonin stimulation. PTH, the major hormone increasing calcium reabsorption in the kidney, activates this chloride channel in CCD cells (49). The mechanism of activation of this chloride channel would require 
gene expression. Taken together, these data suggest that $\mathrm{ClC}-5$ could be the chloride channel involved in this mechanism since PTH also enhances its expression in vivo. However, other chloride channels with similar properties, such as the closely related ClC-3, are also expressed in CCD cells $(32,53)$. Therefore, it still is necessary to determine the molecular identity of the channel reported by Gesek and Friedman (49).

$\mathrm{ClC}-5$ protein was detected in the plasma membrane as well as in immediately early endosomes of the $S_{3}$ segments and on the apical membrane of the CCD cells of rat kidney $(33,44)$. It is well known that these segments participate in the transcellular mechanisms of calcium reabsorption (51). As mentioned above, the loss of ClC-5's function leads to hypercalciuria, a widespread symptom in XLN (14-17). Although failure of calcium reabsorption is a good hypothesis to explain the hypersaturation of urine (and then calculus formation) some clinical finding do not agree with the animal model proposed by Silva and coworkers (52).

Patients with XLN show elevated serum vitamin $\mathrm{D}\left(1 \alpha, 25(\mathrm{OH})_{2}\right.$ vitamin $\mathrm{D}_{3}$ or calcitriol) and normal plasma PTH levels, a fact that is not expected for patients with excessive calcium excretion. These clinical observations lead to a speculation that hypercalciuria could be a secondary mechanism due to excessive intestinal reabsorption enhanced by calcitriol $(54,55)$. This hypothesis was explored by Luyckx and coworkers (47) who produced an animal (mouse) model with lower expression of the $\mathrm{ClC}-5$ channel. On a calcium-restricted diet these mice have a lower urinary calcium/creatinine ratio. The authors suggest that enhanced calcium reabsorption in the intestine (but not the decrease in calcium reabsorption in the kidney) leads to an increase in calcium filtered by the kidney glomeruli and then hypercalciuria.

In agreement with this hypothesis is the fact that $\mathrm{ClC}-5$ is expressed in the intestine, mainly in rat colon and a human colon- derived cell line HT-29 $(37,48,52)$. It may be possible that $\mathrm{ClC}-5$ acts on intestinal calcium absorption as well as on kidney calcium reabsorption. However, an enhancement in the intestinal absorption of calcium would be followed by an increase in serum calcium compared to control mice. Nevertheless, this enhancement in serum calcium does not take place in mice or in XLN patients. Also, an excess of calcium is excreted in feces by Dent's disease patients (14$17,52,54)$. Although the intestinal component relating $\mathrm{ClC}-5$ dysfunction to kidney stones may be an important factor for the pathogenesis of nephrolithiasis, further studies are necessary to test this hypothesis.

\section{Future perspectives and concluding remarks}

Up to now, approximately 40 papers have been published about the $\mathrm{ClC}-5$ chloride channel. Many of them have explored and characterized the mutations responsible for the several variants of XLN $(20,21,26,28,30$, 56-59). Very few papers have focused on the physiological role and regulation of this channel $(35,47,49)$. On the other hand, the structure and function of $\mathrm{ClC}-5$ have not been studied as extensively as for the other members of the ClC family $(22,23)$.

We are aware that many experiments should be done to address all the questions raised since the cloning of ClC- 5 by Thakker and coworkers $(18,19)$. The possible roles attributed to $\mathrm{ClC}-5$ need further investigation and represent a growing area of research. Important questions need to be answered: 1) Why does XLN, being an Xlinked recessive disease, show symptoms in female carriers? 2) Why do different mutants exhibit different phenotypes? 3) Does hypercalciuria lead to body calcium and bone mass loss, and thus to a rickety phenotype in children?

Knockout mice could be a good model for answering the first question. Except for 
the mice with lower $\mathrm{ClC}-5$ expression obtained by Luyckx and coworkers (47), no other animal model has been developed. However, it would not be a surprise if ClC-5 knockout mice did not present any of the symptoms of the human disease. Moreover, the $\mathrm{ClC}-5$ chromosomal localization is still unknown. As long as mice are not syngeneic to humans, it is possible that the murine $\mathrm{ClC}$ 5's locus is not located on chromosome X. This would impair a genetic analysis of carrier females and their offspring. This pedigree analysis is essential to investigate the inheritance of genetic diseases and it has been done for XLN as well (24). But if mouse $\mathrm{ClC}-5$ is located on chromosome $\mathrm{X}$ it would be a good model for the pattern of inheritance and the variations of symptoms.

Different members of the $\mathrm{ClC}$ chloride channel family have been intensively studied in terms of structure and function $(22,23)$. Although ClC-5 may have a structure and function pattern similar to that of other members of the family, such studies have not been done on ClC-5. Similar studies are necessary because they could help clarify why different mutations of ClCN5 may result in such different phenotypes $(20,21,26$, 28,30,56-60).

Rickets are not so common as hypercalciuria and nephrolithiasis. However, the rickety phenotype is common in Europe $(20,21$,
26,27,30,57-59). Recent data suggest a role of ClC-5 in calcium metabolism $(47,52)$. If ClC -5 is actually involved in calcium metabolism it could be expected to be expressed in bone, the major site of calcium storage. So far its expression has not been analyzed in bone or in bone cells. As we mentioned above, ClC-5 has a different pattern of expression varying from a widespread channel expressed in Xenopus (51) to an almost tissue-specific channel in humans $(19,48,50)$. It is possible that $\mathrm{ClC}-5$ may also have a role in human bone metabolism if it is expressed in bone. This could represent more evidence of the growing dysfunction observed in some $\mathrm{XLN}$ patients. However, if $\mathrm{ClC}-5$ has a role in bone metabolism a growth deficiency would be expected in mice with lower expression of $\mathrm{ClC}-5$, but this is not the case (47). Thus, once again, a fully characterized animal model would be very important for the study of XLN phenotypes, or might perhaps raise more questions about the role of this chloride channel in this complex disease.

\section{Acknowledgments}

We thank Dr. Doris Rosenthal for a critical reading of the manuscript. We also thank Angelo T. Malaquias for the reproduction of the figures.

\section{References}

1. Prien EL (1949). Studies in urolithiasis. J ournal of Urology, 61: 821-836.

2. Souncie JM, Thun MJ, Coates RJ, MacClellan W \& Austin H (1994). Demographic and geographic variability of kidney stones in the United States. Kidney International, 46: 893-899.

3. Sutor DJ, Wooley SE \& Illingworth JJ (1974). Some aspects of the adult urinary stone problem in Great Britain and Northern Ireland. British J ournal of Urology, 46: 275-288.

4. Koide $\mathrm{T}$, Oka $\mathrm{T}$, Takaha $\mathrm{M} \&$ Sooda $\mathrm{T}$ (1986). Urinary tract stone disease in modern J apan. European Urology, 12: 403-
407.

5. Araújo NC \& Rebelo MAP (1994). Estudo da taxa de recorrência em pacients com litíase renal. J ornal Brasileiro de Nefrologia, 16: 156-160.

6. Coe FL, Keck J \& Norton ER (1977). The natural history of calcium urolithiasis. J ournal of the American Medical Association, 238: 1519-1523.

7. Giugliani R \& Ferrari I (1980). Metabolic factors in urolithiasis: a study in Brazil. J ournal of Urology, 124: 503-507.

8. Khan SR \& Glenton PA (1995). Deposition of calcium phosphate and calcium oxalate crystals in the kidney. J ournal of Urology,
153: 811-817.

9. Kok DJ \& Khan SR (1994). Calcium oxalate nephrolithiasis, a free or fixed particle disease. Kidney International, 46: 847-854.

10. Pras E, Arber A, Aksentijevich I, Katz G, Schapiro J M, Prosen L, Gruberg L, Harel D, Liberman U, Weissenbach J , Pras M \& Kastner DL (1994). Localization of a gene causing cystinuria to chromosome $2 \mathrm{p}$. Nature Genetics, 6: 415-418.

11. Thakker RV (1998). Disorders of the calcium-sensing receptor. Biochimica et Biophysica Acta, 1448: 166-170.

12. Scheinman SJ, Guay-Woodford LM, 
Thakker RV \& Warnock DG (1999). Genetic disorders of renal electrolyte transport. New England J ournal of Medicine, 340: 1177-1187.

13. Thakker RV (1999). Chloride channels in renal disease. Advances in Nephrology from the Necker Hospital, 29: 289-298.

14. Scheinman SJ (1998). X-linked hypercalciuric nephrolithiasis: clinical syndromes and chloride channel mutations. Kidney International, 53: 3-17.

15. Dent CE \& Friedman M (1964). Hypercalciuric rickets associated with renal tubular damage. Archives of Disease in Childhood, 39: 240-249.

16. Thakker RV (1998). The role of renal chloride channel mutations in kidney stone disease and nephrocalcinosis. Current Opinion in Nephrology and Hypertension, 7: 385-388.

17. Thakker RV (1997). Chloride channels cough up. Nature Genetics, 17: 125-127.

18. Pook MA, Wrong O, Wooding $C$, Norden AG, Feest TG \& Thakker RV (1993). Dent's disease, a renal Fanconi syndrome with nephrocalcinosis and kidney stones, is associated with a microdeletion involving DXS255 and maps to Xp11.22. Human Molecular Genetics, 2: 2129-2134.

19. Fisher SE, van Bakel I, Lloyd SE, Pearce SH, Thakker RV \& Craig IW (1995). Cloning and characterization of CLCN5, the human kidney chloride channel gene implicated in Dent disease (an X-linked hereditary nephrolithiasis). Genomics, 29: 598-606.

20. Lloyd SE, Gunther W, Pearce SH, Thomson A, Bianchi ML, Bosio M, Craig IW, Fisher SE, Scheinman SJ, Wrong O, J entsch TJ \& Thakker RV (1997). Characterization of renal chloride channel, CLCN5 mutations in hypercalciuric nephrolithiasis (kidney stones) disorders. Human Molecular Genetics, 6: 1233-1239.

21. Igarashi T, Gunther W, Sekine T, Inatomi J, Shiraga H, Takahashi S, Suzuki J , Tsuru N, Yanagihara T, Shimazu M, J entsch TJ \& Thakker RV (1998). Functional characterization of renal chloride channel, CLCN5, mutations associated with Dent's J apan disease. Kidney International, 54: 1850-1856.

22. J entsch TJ (1994). Structure and function of $\mathrm{ClC}$ chloride channels. J apanese J ournal of Physiology, 44: S1-S2.

23. J entsch TJ, Gunther W, Pusch $M$ \& Schwappach B (1995). Properties of voltage-gated chloride channels of the $\mathrm{CIC}$ gene family. J ournal of Physiology, 482: 19S-25S.

24. George J r AL (1998). Chloride channels and endocytosis: CIC-5 makes a dent. Proceedings of the National Academy of Sciences, USA, 95: 7843-7845.

25. Vandewalle $A$, Cluzeaud $F$, Bens $M$, Kieferle S, Steinmeyer K \& J entsch TJ (1997). Localization and induction by dehydration of $\mathrm{CIC}-\mathrm{K}$ chloride channels in the rat kidney. American J ournal of Physiology, 272: F678-F688.

26. Lloyd SE, Pearce SH, Fisher SE, Steinmeyer K, Schwappach B, Scheinman SJ , Harding B, Bolino A, Devoto M, Goodyer P, Rigden SP, Wrong O, J entsch TJ , Craig IW \& Thakker RV (1996). A common molecular basis for three inherited kidney stone diseases. Nature, 379: 445-449.

27. Kumar R (1998). ClC-5 chloride channels and renal disease. Kidney International, 53: 228-229.

28. Morimoto $T$, Uchida $S$, Sakamoto $H$, Kondo $Y$, Hanamizu H, Fukui M, Tomino Y, Nagano N, Sasaki S \& Marumo F (1998). Mutations in CICN5 chloride channel in J apanese patients with low molecular weight proteinuria. J ournal of the American Society of Nephrology, 9: 811-818.

29. Galaske RG, Van Liew J B \& Feld LG (1979). Filtration and reabsorption of endogenous low-molecular-weight protein in the rat kidney. Kidney International, 16: 394-403.

30. Nakazato H, Yoshimuta J, Karashima S, Matsumoto S, Endo F, Matsuda I \& Hattori S (1999). Chloride channel CLCN5 mutations in J apanese children with familial idiopathic low molecular weight proteinuria. Kidney International, 55: 63-70.

31. Norden AG, Scheinman SJ, DeschodtLanckman MM, Lapsley M, Nortier J L, Thakker RV, Unwin RJ \& Wrong O (2000). Tubular proteinuria defined by a study of Dent's (CICN5 mutation) and other tubular diseases. Kidney International, 57: 240249.

32. Obermuller N, Gretz N, Kriz W, Reilly RF \& Witzgall R (1998). The swelling-activated chloride channel $\mathrm{ClC}-2$, the chloride channel CIC-3, and CIC-5, a chloride channel mutated in kidney stone disease, are expressed in distinct subpopulations of renal epithelial cells. J oumal of Clinical Investigation, 101: 635-642.

33. Gunther W, Luchow A, Cluzeaud F, Vandewalle A \& J entsch TJ (1998). CIC-5, the chloride channel mutated in Dent's disease, colocalizes with the proton pump in endocytically active kidney cells. Proceedings of the National Academy of Sciences, USA, 95: 8075-8080.

34. Luyckx VA, Goda FO, Mount DB, Nishio T, Hall A, Hebert SC, Hammond TG \& Yu AS
(1998). Intrarenal and subcellular localization of rat ClC5. American J ournal of Physiology, 275 (Part 2): F761-F769.

35. Devuyst O, Christie PT, Courtoy PJ , Beauwens R \& Thakker RV (1999). Intrarenal and subcellular distribution of the human chloride channel, CIC-5, reveals a pathophysiological basis for Dent's disease. Human M olecular Genetics, 8: 247257.

36. Lamb FS, Clayton GH, Liu BX, Smith RL, Barna TJ \& Schutte BC (1999). Expression of CLCN voltage-gated chloride channel genes in human blood vessels. J ournal of Molecular and Cellular Cardiology, 31: 657-666.

37. von Weikersthal SF, Barrand MA \& Hladky SB (1999). Functional and molecular characterization of a volume-sensitive chloride current in rat brain endothelial cells. J ournal of Physiology, 516: 75-84.

38. Lieske J C, Swift H, Martin T, Patterson B \& Toback FG (1994). Renal epithelial cells rapidly bind and internalize calcium oxalate monohydrate crystals. Proceedings of the National Academy of Sciences, USA, 91: 6987-6991.

39. Campos AH \& Schor N (2000). Mechanisms involved in calcium oxalate endocytosis by Madin-Darby canine kidney cells. Brazilian J ournal of Medical and Biological Research, 33: 111-118.

40. Steinmeyer K, Schwappach B, Bens M, Vandewalle A \& J entsch TJ (1995). Cloning and functional expression of rat CLC5 , a chloride channel related to kidney disease. J ournal of Biological Chemistry, 270: 31172-31177.

41. Sakamoto H, Kawasaki M, Uchida S Sasaki S \& Marumo F (1996). Identification of a new outwardly rectifying $\mathrm{Cl}$ channel that belongs to a subfamily of the $\mathrm{CIC} \mathrm{Cl-channels.} \mathrm{J} \mathrm{ournal} \mathrm{of} \mathrm{Biological}$ Chemistry, 271: 10210-10216.

42. Shapiro LJ (1993). The genetic basis of Xlinked nephrolithiasis: Leaving no stone unturned. J ournal of Clinical Investigation, 91: 2351-2357.

43. Hebert SC (1996). Crystal-clear chloride channels. Nature, 379: 398-399.

44. Sakamoto H, Sado Y, Naito I, Kwon TH, Inoue S, Endo K, Kawasaki M, Uchida S, Nielsen S, Sasaki S \& Marumo F (1999). Cellular and subcellular immunolocalization of ClC-5 channel in mouse kidney: colocalization with $\mathrm{H}^{+}$-ATPase. American J ournal of Physiology, 277 (Part 2): F957F965.

45. Friedrich $\mathrm{T}$, Breiderhoff $\mathrm{T} \&$ J entsch $\mathrm{T}$ J (1999). Mutational analysis demonstrates that $\mathrm{CIC}-4$ and $\mathrm{ClC}-5$ directly mediate 
plasma membrane currents. J ournal of Biological Chemistry, 274: 896-902.

46. Mo L, Hellmich HL, Fong P, Wood T, Embesi J \& Wills NK (1999). Comparison of amphibian and human CIC-5: similarity of functional properties and inhibition by external pH. J ournal of Membrane Biology, 168: 253-264.

47. Luyckx VA, Leclercq B, Dowland LK \& Yu AS (1999). Diet-dependent hypercalciuria in transgenic mice with reduced CLC5 chloride channel expression. Proceedings of the National Academy of Sciences, USA, 96: 12174-12179.

48. Hagos Y, Krick W \& Burckhardt D (1999). Chloride conductance in HT29 cells: investigations with apical membrane vesicles and RT-PCR. Pflügers Archives, G437: 724-730.

49. Gesek FA \& Friedman PA (1993). Calcitonin stimulates calcium transport in distal convoluted tubule cells. American J ournal of Physiology, 33: F744-F751.

50. Lindenthal S, Schmieder S, Ehrenfeld J \& Wills NK (1997). Cloning and functional expression of a $\mathrm{ClC} \mathrm{Cl-channel} \mathrm{from} \mathrm{the}$ renal cell line A6. American J ournal of Physiology, 273 (Part 1): C1176-C1185.

51. Hugi K, Bonjour J -P \& Fleisch H (1979). Renal handling of calcium: influence of parathyroid hormone and 1,25 dihydroxyvitamin D3. American J ournal of Physiology, 236: F349-F356.

52. Silva IV, Blaisdell CJ, Guggino SE \& Guggino WB (2000). PTH regulates the expression of $\mathrm{ClC}-5$ chloride channel in the kidney. American J ournal of Physiology, 278: F238-F245.

53. Sasaki S, Uchida S, Kawasaki M, Sasaki S, Adachi S \& Marumo F (1994). ClC family in the kidney. J apanese J ournal of Physiology, 44: S3-S8.

54. Wrong $O$, Norden AGW \& Feest TG (1994). Dent's disease: A familial proximal renal tubular syndrome with low-molecular-weight proteinuria, hypercalciuria, nephrocalcinosis, metabolic bone disease, progressive renal failure, and marked male predominance. Quarterly J ournal of Medicine, 87: 473-493.

55. Langlois V, Bernard C, Scheinman SJ, Thakker RV, Cox J P \& Goodyer PR (1998). Clinical features of $X$-linked nephrolithiasis in childhood. Pediatric Nephrology, 12: 625-629.

56. Akuta N, Lloyd SE, Igarashi $\mathrm{T}$, Shiraga $\mathrm{H}$, Matsuyama T, Yokoro S, Cox JP \& Thakker RV (1997). Mutations of CICN5 in J apanese children with idiopathic low molecular weight proteinuria, hypercalci- uria and nephrocalcinosis. Kidney International, 52: 911-916.

57. Lloyd SE, Pearce SH, Gunther W, Kawaguchi $\mathrm{H}$, Igarashi T, Jentsch TJ \& Thakker RV (1997). Idiopathic low molecular weight proteinuria associated with hypercalciuric nephrocalcinosis in J apanese children is due to mutations of the renal chloride channel (CICN5). J ournal of Clinical Investigation, 99: 967-974.

58. Bosio M, Bianchi ML, Lloyd SE \& Thakker RV (1999). A familial syndrome due to Arg648Stop mutation in the X-linked renal chloride channel gene. Pediatric Nephrology, 13: 278-283.

59. Cox J P, Yamamoto K, Christie PT, Wooding $C$, Feest $T$, Flinter FA, Goodyer PR, Leumann E, Neuhaus T, Reid C, Williams PF, Wrong O \& Thakker RV (1999). Renal chloride channel, CLCN5, mutations in Dent's disease. J ournal of Bone and Mineral Research, 14: 1536-1542.

60. Scheinman SJ, Cox J P, Lloyd SE, Pearce $\mathrm{SH}$, Salenger PV, Hoopes RR, Bushinsky DA, Wrong $O$, Asplin J R, Langman CB, Norden AG \& Thakker RV (2000). Isolated hypercalciuria with mutation in CICN5: Relevance to idiopathic hypercalciuria. Kidney International, 57: 232-239. 